\title{
A Comparison of the Effects of X-Ray and Proton Irradiation on the Performance of SiGe Precision Voltage References
}

\author{
Laleh Najafizadeh, Student Member, IEEE, Akil K. Sutton, Student Member, IEEE, \\ Ryan M. Diestelhorst, Student Member, IEEE, Marco Bellini, Student Member, IEEE, Bongim Jun, Member, IEEE, \\ John D. Cressler, Fellow, IEEE, Paul W. Marshall, Member, IEEE, and Cheryl J. Marshall
}

\begin{abstract}
A comprehensive investigation of the performance dependencies of irradiated SiGe precision voltage reference circuits on 1) total ionizing dose (TID), 2) circuit topology, and 3) radiation source is presented. Two different bandgap voltage references were designed using a first-generation (50-GHz) SiGe BiCMOS technology platform, and subsequently exposed to $\mathrm{X}$-rays at doses of $1080 \mathrm{krad}\left(\mathrm{SiO}_{2}\right)$ and $5400 \mathrm{krad}\left(\mathrm{SiO}_{2}\right)$. The degradation in circuit performance following $\mathrm{X}$-ray irradiation depends on both the TID level and the chosen circuit topology. Measurement results show that large TID levels can significantly shift the magnitude of the output voltage. Explanations for the observed shifts are provided by utilizing detailed analyses of the two circuit topologies and considering device-to-circuit interactions. The primary factor responsible for the difference in the circuit response before and after irradiation can be attributed to the excess base leakage current in the SiGe HBT. To investigate the impact of radiation source, the circuit topology showing the worst-case degradation from the $\mathrm{X}$-ray experiment was independently exposed to $63-\mathrm{MeV}$ protons at the same effective TID level. A clear source dependence in the circuit response was observed, and possible origins of this behavior are identified.
\end{abstract}

Index Terms-BiCMOS analog integrated circuits, heterojuction bipolar transistors, ionization damage, proton radiation effects, SiGe, SiGe HBTs, X-rays.

\section{INTRODUCTION}

$\mathbf{S}$ ILICON-GERMANIUM heterojunction bipolar transistors (SiGe HBTs), because they possess inherent multi-Mrad total dose tolerance and have performance comparable with that of III-V devices while supporting much higher levels of integra-

\footnotetext{
Manuscript received July 20, 2007; revised October 1, 2007. This work was supported by the NASA SiGe ETDP program, the Defense Threat Reduction Agency under the Radiation Hardened Microelectronics Program, NASA-GSFC under the NASA Electronic Parts and Packaging (NEPP) program, an AFOSR MURI program, and the Georgia Electronic Design Center at Georgia Tech.

L. Najafizadeh, A. K. Sutton, R. M. Diestelhorst, M. Bellini, and J. D. Cressler are with the School of Electrical and Computer Engineering, Georgia Institute of Technology, Atlanta, GA 30308 USA (e-mail: laleh@ece.gatech.edu; asutton@ece.gatech.edu; ryan@ece.gatech.edu; bellini@ece.gatech.edu; cressler@ece.gatech.edu).

B. Jun was with Georgia Institute of Technology, Atlanta, GA 30332 USA. She is now with Spectrolab, Inc., Sylmar, CA 91342 USA (e-mail: bjun@ @pectrolab.com).

P. W. Marshall is a consultant to NASA-GSFC, Greenbelt, MD 20771 USA (e-mail: PWMarshall@aol.com).

C. J. Marshall is with the NASA-GSFC, Greenbelt, MD 20771 USA (e-mail: CMarshall2@aol.com).

Color versions of one or more of the figures in this paper are available online at http://ieeexplore.ieee.org.

Digital Object Identifier 10.1109/TNS.2007.910858
}

tion, have become prime contenders for a wide variety of spacebased circuit applications [1]. Many such space systems are required to operate under extreme environmental conditions (e.g., under radiation exposure and over wide temperature ranges). Precision bandgap voltage references (BGRs) are extensively used in a wide variety of circuits required for space applications, including high-resolution digital-to-analog (D/A) or analog-todigital (A/D) converters. Any variations in the reference voltage provided by the BGRs used in such sensitive data conversion circuits will directly affect their resolution, and as a result, BGR circuits must provide very stable outputs under any extreme conditions encountered.

The degradation of analog circuits due to irradiation has been previously investigated in [2]-[10]. Most of these studies have only considered Si bipolar junction transistor (Si BJT) circuits [2]-[8]. Proton radiation response of SiGe circuits was investigated in [9], [10] and showed only minor changes in the SiGe BGR performance up to total ionization dose (TID) of $3 \mathrm{Mrad}(\mathrm{Si})$. However, no studies have been carried out to investigate the effects of radiation source on the performance of $\mathrm{SiGe}$ circuits. At the device level, differences in the degradation induced by $10 \mathrm{keV} \mathrm{X}$-rays and $63.3 \mathrm{MeV}$ protons have been observed [11], [12], and provides clear motivation to determine if these source dependent differences will be encountered at the circuit level, affecting the overall circuit performance.

In this paper, we present, for the first time, a comprehensive investigation of the performance dependencies of irradiated SiGe BGR circuits on TID level and radiation source. Two types of SiGe BGR circuits were designed and exposed to X-rays at two different TID levels, $1080 \mathrm{krad}\left(\mathrm{SiO}_{2}\right)$ and 5400 $\operatorname{krad}\left(\mathrm{SiO}_{2}\right)$. Degradation due to $10 \mathrm{keV} \mathrm{X-rays} \mathrm{is} \mathrm{shown} \mathrm{to} \mathrm{be}$ dependent on both TID level and circuit topology. The origins of these dependencies are investigated and explained through detailed circuit analysis. To investigate the effects of radiation source on circuit performance, the circuit topology showing the worst-case degradation from the X-ray experiment was exposed to $63.3 \mathrm{MeV}$ protons to the same effective TID level. Measurement results from proton irradiation are compared with those from the X-ray experiment and it is shown that circuit response is indeed radiation source dependent. Possible explanations for this observation are discussed.

\section{Process Technology}

The technology used to implement the SiGe BGR circuits is a commercially-available, first-generation $\mathrm{SiGe}$ (IBMs $\mathrm{SiGe}$ 


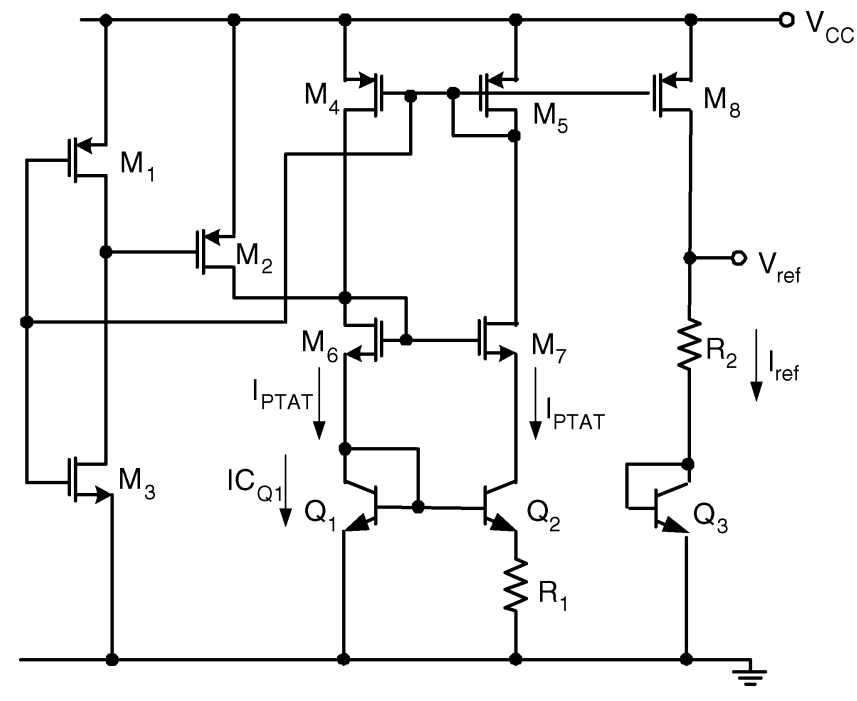

Fig. 1. Schematic of the uncompensated SiGe bandgap reference.

5AM) BiCMOS technology. This four-level metal IC platform features SiGe HBTs with an emitter width of $0.5 \mu \mathrm{m}$ and a unity gain cut-off frequency and maximum oscillation frequency of $45 \mathrm{GHz}$ and $60 \mathrm{GHz}$ at room temperature, respectively. CMOS transistors with a nominal $\mathrm{L}_{\mathrm{eff}}$ of $0.35 \mu \mathrm{m}$, as well as polysilicon and diffused resistors, and various capacitors are also available. Total proton dose tolerance of the SiGe HBTs from this technology has been reported previously in [13] and [14].

\section{CirCUIT DesCRIPTION}

To better understand the effects of irradiation on the performance of SiGe voltage references, two different BGR circuit topologies were implemented using first generation $\mathrm{SiGe}$ (IBMs SiGe 5AM) BiCMOS technology platform. Fig. 1 shows the schematic of the first-order BGR, in which no curvature compensation technique is employed [15]. Transistors $M_{1}-M_{3}$ form the start-up circuit and transistors $M_{4}-M_{7}$ and $Q_{1}-Q_{2}$, along with the resistor $R_{1}$, generate the bias current for the following stage, which is proportional to the absolute temperature (PTAT). Each SiGe HBT used in this circuit, except for $Q_{2}$, consists of four parallel copies of $0.5 \times 2.5 \mu \mathrm{m}^{2} \mathrm{SiGe}$ HBTs. The emitter area of transistor $Q_{2}$ is eight times larger than that of the other transistors and as a result, the PTAT bias current is obtained as

$$
I_{\mathrm{PTAT}}=\frac{V_{\mathrm{BE}, 1}-V_{\mathrm{BE}, 2}}{R_{1}}=\frac{\Delta V_{\mathrm{BE}}}{R_{1}}
$$

where $\Delta V_{\mathrm{BE}}$ is the difference between the base-emitter voltages of transistors $Q_{1}$ and $Q_{2}$, and is a voltage that is proportional to the absolute temperature. Transistors $M_{4}-M_{5}$ and $M_{6}-$ $M_{7}$ are identically-sized pairs. The PTAT bias current is then amplified through transistor $M_{8}$, with the amplification factor $k=(W / L)_{M_{8}} /(W / L)_{M_{5}}$, generating $I_{\text {ref }}$ given as

$$
I_{\text {ref }}=k I_{\text {PTAT }} \text {. }
$$

The output voltage of the uncompensated BGR, $V_{\text {ref }}$, can then be expressed as

$$
V_{\mathrm{ref}}=V_{\mathrm{BE}, 3}+R_{2} I_{\mathrm{ref}}=V_{\mathrm{BE}, 3}+k \frac{\Delta V_{\mathrm{BE}}}{R_{1}} R_{2} .
$$

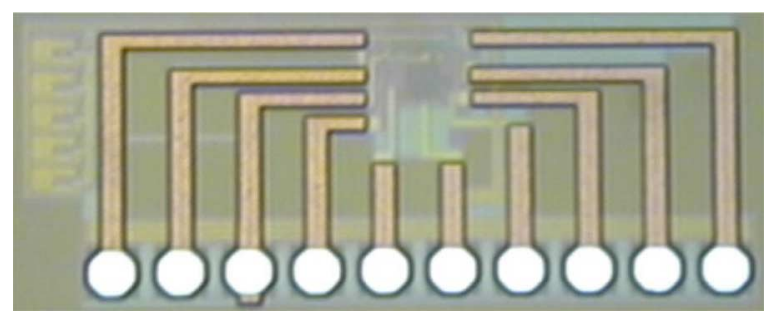

Fig. 2. Die micrograph of the uncompensated SiGe bandgap reference.

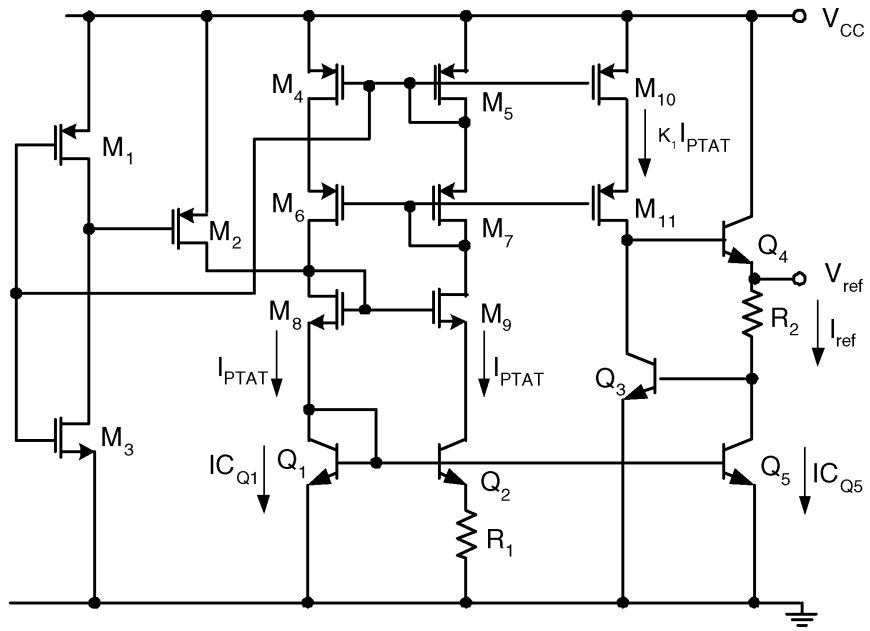

Fig. 3. Schematic of the curvature compensated SiGe bandgap reference.

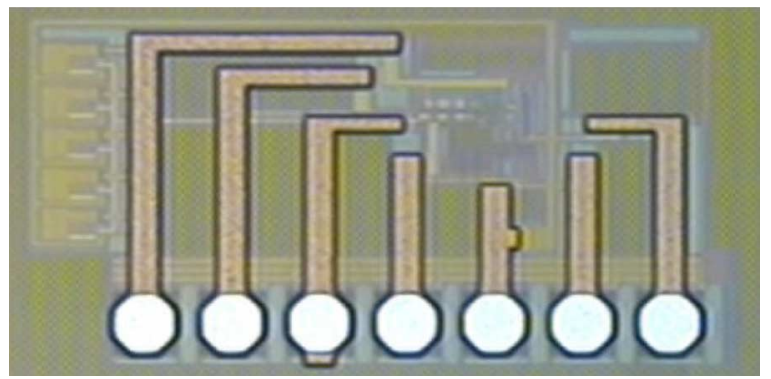

Fig. 4. Die micrograph of the curvature compensated SiGe bandgap reference.

The voltage $V_{\text {ref }}$ is almost equal to the bandgap voltage of SiGe, extrapolated to $0 \mathrm{~K}$. This is because the negative temperature dependence of the base-emitter voltage of transistor $Q_{3}$ is to first-order canceled by the PTAT voltage generated across resistor $R_{2}$. Note that both resistors $R_{1}$ and $R_{2}$ are implemented using the same material (here, heavily doped $p$-type polysilicon), and therefore, the ratio $R_{2} / R_{1}$ in (3) is temperature independent. The micrograph of this SiGe BGR circuit is shown in Fig. 2.

Since the base-emitter voltage of a SiGe HBT is a complex function of temperature, containing many higher order terms, the output voltage of the first-order BGR will have some inherent temperature drift. To improve the temperature stability of the output voltage of the first-order BGR, several techniques have been developed [16]-[19]. The schematic and the die micrograph for the voltage reference that employs one of these compensation techniques [16] are shown in Figs. 3 and 4, respectively. We refer to this circuit as the compensated BGR. In 
this circuit, the temperature characteristics of the current gain of transistor $Q_{3}$ are exploited for curvature compensation of the output voltage. Similar to the first-order BGR, a PTAT current is generated through transistors $M_{4}-M_{9}$ and $Q_{1}-Q_{2}$, along with resistor $R_{1}$, and follows (1). This PTAT current is then mirrored and amplified through the current mirrors $M_{10}-M_{11}$ and transistor $Q_{5}$ into the following last two stages. The resulting output voltage can be estimated as [16]

$$
\begin{aligned}
V_{\text {ref }} & \approx V_{\mathrm{BE}, 3}+R_{2} I_{\mathrm{ref}} \\
& =V_{\mathrm{BE}, 3}+k_{1} \frac{\Delta V_{\mathrm{BE}}}{R_{1}} R_{2}+k_{2} \frac{\Delta V_{\mathrm{BE}}}{R_{1} \beta_{Q, 3}} R_{2}
\end{aligned}
$$

where $k_{1}$ and $k_{2}$ are the amplification factors of the PTAT current in the last two stages, and $\beta_{Q, 3}$ is the current gain of transistor $Q_{3}$. The current gain of transistor $Q_{3}$ is almost an exponential function of temperature and therefore, the third term in (4) helps to compensate the nonlinear terms in $V_{\mathrm{BE}, 3}$. Note that because we use cascode current mirrors, the line regulation and the power supply rejection ratio of this circuit are significantly improved compared to the first-order BGR. Both circuits were designed to operate with a power supply of $3.3 \mathrm{~V}$ and in both cases, careful layout techniques were employed to reduce transistor mismatch effects.

\section{X-RAY IRRADIATION}

In this section, we investigate the effects of $10 \mathrm{keV} \mathrm{X-ray} \mathrm{ir-}$ radiation on the performance of both the first-order and the compensated $\mathrm{SiGe}$ voltage references described in the previous section. The experimental procedure as well as the measurement results are presented. It is shown that the degradation due to $\mathrm{X}$-ray exposure is dependent on both TID level and circuit topology, and the origins of these dependencies are explained through detailed circuit analysis considering device-to-circuit interactions.

\section{A. Experiment}

The circuits and devices intended for this X-ray experiment were mounted into 28-pin ceramic DIP packages, wire-bonded, and fully characterized both prior to and subsequent to irradiation. A closed-cycle helium cryostat was used for characterization over temperature. X-ray irradiation was performed at Vanderbilt University using an ARACOR X-ray test system. Circuits under operating bias and devices in forward-active bias configuration were irradiated at room temperature with $10 \mathrm{keV}$ $\mathrm{X}$-rays to TID of $1080 \mathrm{krad}\left(\mathrm{SiO}_{2}\right)$ and $5400 \mathrm{krad}\left(\mathrm{SiO}_{2}\right)$, at the dose rate of $60 \mathrm{krad}\left(\mathrm{SiO}_{2}\right) / \mathrm{min}$. All electrical measurements were performed using an Agilent 4155 Semiconductor Parameter Analyzer.

\section{B. Results}

The output voltages of the two SiGe BGR circuits described in Section III were measured before and after X-ray irradiation, at different temperatures ranging from $27{ }^{\circ} \mathrm{C}$ down to $-230{ }^{\circ} \mathrm{C}$. Measurement results are shown in Figs. 5-8. Figs. 5 and 6 show the output voltage of the first-order BGR and the compensated BGR, respectively, before and after irradiation to total dose value of $1080 \mathrm{krad}\left(\mathrm{SiO}_{2}\right)$. As can be seen, a small

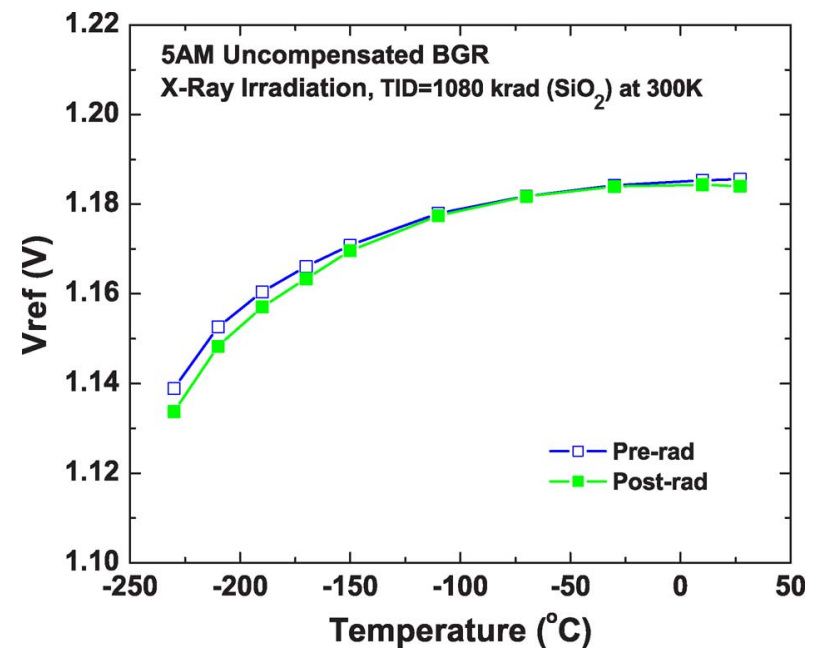

Fig. 5. Output voltage of uncompensated BGR before and after X-ray irradiation with TID $=1080 \mathrm{krad}\left(\mathrm{SiO}_{2}\right)$.

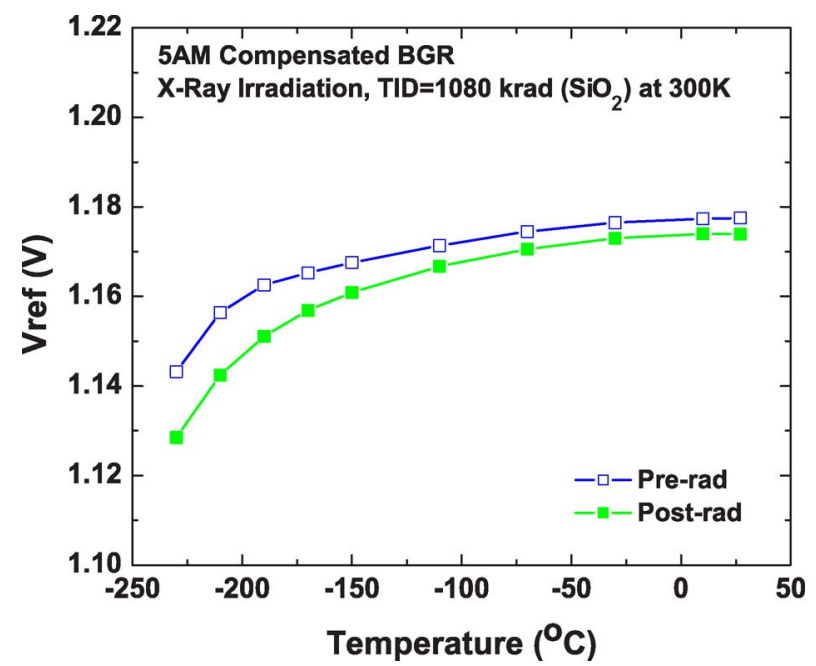

Fig. 6. Output voltage of compensated BGR before and after X-ray irradiation with $\mathrm{TID}=1080 \mathrm{krad}\left(\mathrm{SiO}_{2}\right)$

shift in the output voltage of the compensated BGR is observed across temperature after irradiation. The change in the output voltage of the first-order circuit is almost negligible after X-ray exposure. These figures show that both circuits are quite robust to X-ray exposures up to $1080 \mathrm{krad}\left(\mathrm{SiO}_{2}\right)$. The output voltage of the first-order and the compensated BGRs before and after $\mathrm{X}$-ray irradiation at TID level of $5400 \mathrm{krad}\left(\mathrm{SiO}_{2}\right)$ is shown in Figs. 7 and 8, respectively. Unlike the previous case, the output voltage of both circuits show significant degradation across all temperatures. This shift in the output voltage is more visible in the compensated BGR than in the first-order BGR. Table I summarizes the performance metrics of the two SiGe BGR circuits before and after $\mathrm{X}$-ray irradiation to total dose values of $1080 \mathrm{krad}\left(\mathrm{SiO}_{2}\right)$ and $5400 \mathrm{krad}\left(\mathrm{SiO}_{2}\right)$. Note that the circuits used for the two TID exposure experiments are from two different dies, and the difference among the pre-rad performance metrics is attributed to the on-wafer process variations. The observed degradation in the output voltage of the BGR circuits due to exposure to high dose X-rays could be potentially an 
TABLE I

Performance Metrics of SiGe BGRs Before AND AFter X-RAy IrRADiation

\begin{tabular}{|c|c|c|c|c|c|c|c|c|}
\hline \multirow[t]{2}{*}{ BGR Circuit } & \multicolumn{2}{|c|}{$V_{\text {ref }}(\mathrm{V})$} & \multicolumn{2}{|c|}{$I_{c c}(\mu \mathrm{A})$} & \multicolumn{2}{|c|}{$\begin{array}{l}\mathrm{TC}\left(\mathrm{ppm} /{ }^{\circ} \mathrm{C}\right) \\
(-180: 27)^{\circ} \mathrm{C} \\
\end{array}$} & \multicolumn{2}{|c|}{$\begin{array}{l}\mathrm{TC}\left(\mathrm{ppm} /{ }^{\circ} \mathrm{C}\right) \\
(-70: 27)^{\circ} \mathrm{C}\end{array}$} \\
\hline & pre-rad & post-rad & pre-rad & post-rad & pre-rad & post-rad & pre-rad & post-rad \\
\hline $\begin{array}{c}\text { Uncompensated } \\
\left(\mathrm{TID}=1080 \mathrm{krad}\left(\mathrm{SiO}_{2}\right)\right.\end{array}$ & $\begin{array}{c}1.186 @ 27^{\circ} \mathrm{C} \\
1.163 @-180^{\circ} \mathrm{C}\end{array}$ & $\begin{array}{c}1.184 @ 27^{\circ} \mathrm{C} \\
1.160 @-180^{\circ} \mathrm{C}\end{array}$ & $\begin{array}{l}113.0 @ 27^{\circ} \mathrm{C} \\
51.4 @-180^{\circ} \mathrm{C}\end{array}$ & $\begin{array}{l}113.7 @ 27^{\circ} \mathrm{C} \\
47.9 @-180^{\circ} \mathrm{C}\end{array}$ & 90.3 & 98.0 & 33.08 & 22.6 \\
\hline $\begin{array}{c}\text { Compensated } \\
\left(\mathrm{TID}=1080 \mathrm{krad}\left(\mathrm{SiO}_{2}\right)\right.\end{array}$ & $\begin{array}{c}1.177 @ 27^{\circ} \mathrm{C} \\
1.164 @-180^{\circ} \mathrm{C}\end{array}$ & $\begin{array}{c}1.174 @ 27^{\circ} \mathrm{C} \\
1.154 @-180^{\circ} \mathrm{C}\end{array}$ & $\begin{array}{l}129.9 @ 27^{\circ} \mathrm{C} \\
55.3 @-180^{\circ} \mathrm{C}\end{array}$ & $\begin{array}{l}130.1 @ 27^{\circ} \mathrm{C} \\
52.1 @-180^{\circ} \mathrm{C}\end{array}$ & 55.6 & 82.7 & 26.3 & 29.3 \\
\hline $\begin{array}{c}\text { Uncompensated } \\
\left(\mathrm{TID}=5400 \mathrm{krad}\left(\mathrm{SiO}_{2}\right)\right.\end{array}$ & $\begin{array}{c}1.182 @ 27^{\circ} \mathrm{C} \\
1.164 @-180^{\circ} \mathrm{C}\end{array}$ & $\begin{array}{c}1.168 @ 27^{\circ} \mathrm{C} \\
1.158 @-180^{\circ} \mathrm{C}\end{array}$ & $\begin{array}{l}115.6 @ 27^{\circ} \mathrm{C} \\
52.7 @-180^{\circ} \mathrm{C}\end{array}$ & $\begin{array}{l}109.1 @ 27^{\circ} \mathrm{C} \\
44.3 @-180^{\circ} \mathrm{C}\end{array}$ & 73.5 & 65.4 & 26.2 & 34.1 \\
\hline $\begin{array}{c}\text { Compensated } \\
\left(\mathrm{TID}=5400 \mathrm{krad}\left(\mathrm{SiO}_{2}\right)\right.\end{array}$ & $\begin{array}{l}1.193 @ 27^{\circ} \mathrm{C} \\
1.186 @-180^{\circ} \mathrm{C}\end{array}$ & $\begin{array}{c}1.164 @ 27^{\circ} \mathrm{C} \\
1.152 @-180^{\circ} \mathrm{C}\end{array}$ & $\begin{array}{l}136.9 @ 27^{\circ} \mathrm{C} \\
67.6 @-180^{\circ} \mathrm{C} \\
\end{array}$ & $\begin{array}{l}132.4 @, 27^{\circ} \mathrm{C} \\
52.7 @-180^{\circ} \mathrm{C}\end{array}$ & 39.6 & 74.1 & 10.1 & 25.17 \\
\hline
\end{tabular}

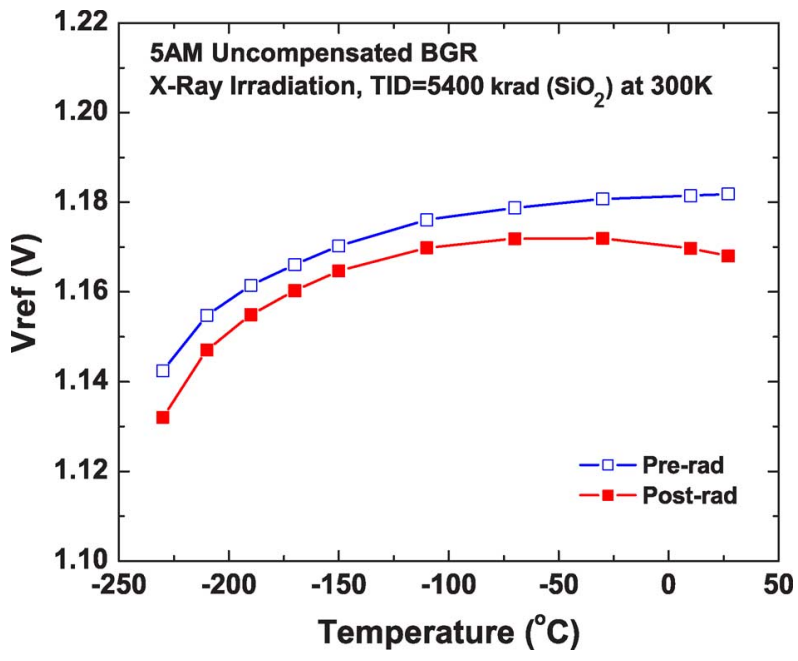

Fig. 7. Output voltage of uncompensated BGR before and after X-ray irradiation with $\mathrm{TID}=5400 \mathrm{krad}\left(\mathrm{SiO}_{2}\right)$.

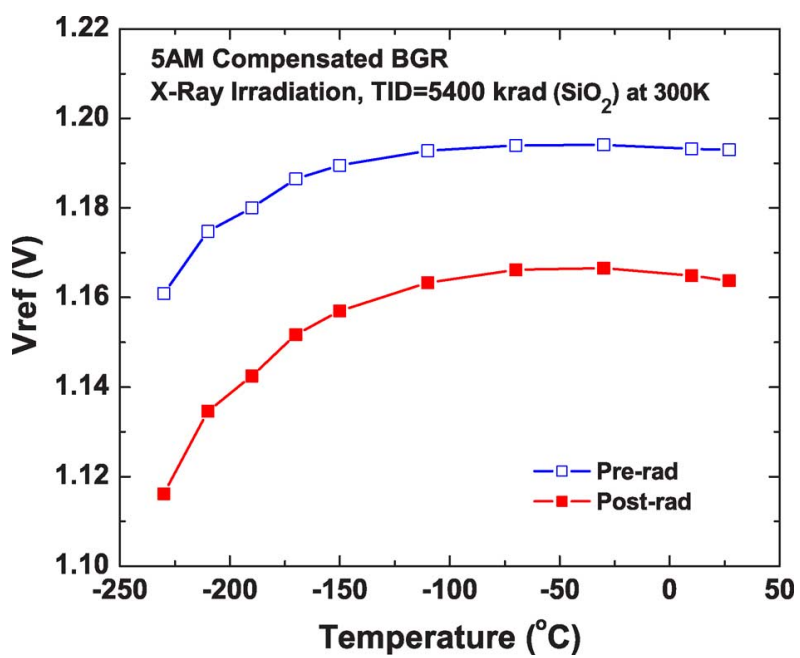

Fig. 8. Output voltage of compensated BGR before and after X-ray irradiation with TID $=5400 \operatorname{krad}\left(\mathrm{SiO}_{2}\right)$.

important issue for certain extreme-exposure applications (e.g., outer planet exploration), since BGR circuits are widely used and often embedded inside sensitive circuits such as A/D and D/A converters, where their individual block-level response may be masked. Therefore, it is important to understand the origins that cause the observed output voltage anomalies.

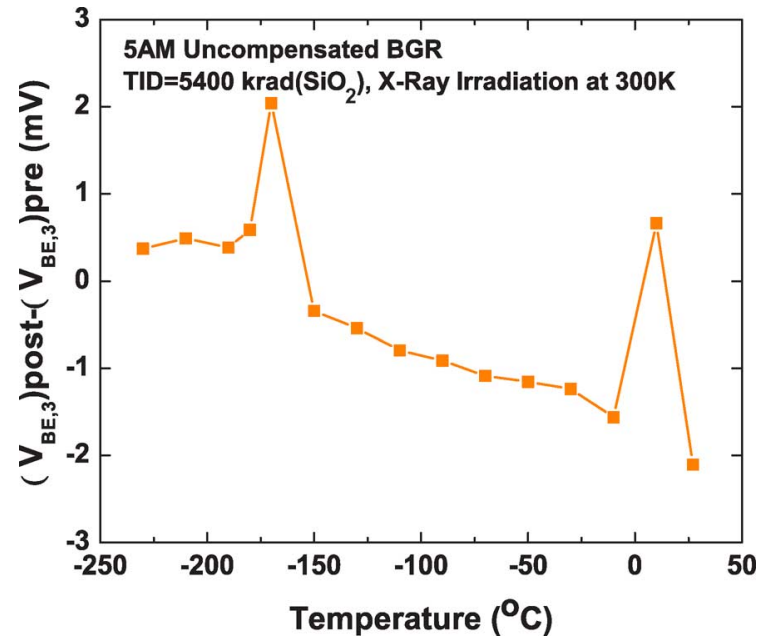

Fig. 9. Change in the difference of $Q_{1}$ and $Q_{2}$ base-emitter voltages of $5 \mathrm{AM}$ SiGe BGR irradiated at room temperature as a function of temperature.

\section{Discussion}

To identify the origins of degradation in the output voltage of SiGe BGR circuits after exposure to high-dose $\mathrm{X}$-rays, we need to carefully examine the two circuit topologies and understand what parameters actually contribute to generating the output voltage. We first start with the first-order BGR circuit, shown in Fig. 1. As can be seen from (3), the base-emitter voltage of transistor $Q_{3}$ and the current $I_{\text {ref }}$ are the main contributors to the magnitude of the output voltage. Note that the value of the resistor $R_{2}$ is $7.4 \mathrm{k} \Omega$ and as a result a small shift of $2 \mu \mathrm{A}$ in the magnitude of the current $I_{\text {ref }}$ will change the magnitude of the output voltage by almost $15 \mathrm{mV}$. The base emitter voltage of transistor $Q_{3}$ was measured prior to and subsequent to irradiation over temperature while the circuit was under operation, as shown in Fig. 9. This figure shows that even for a high TID level of $5400 \mathrm{krad}\left(\mathrm{SiO}_{2}\right)$, the change in the base-emitter voltage of transistor $Q_{3}$ across temperature is small (typically less than 2 $\mathrm{mV}$ ) after irradiation, suggesting that the term $V_{\mathrm{BE}, 3}$ does not contribute to the observed TID dependent output voltage anomalies. The presence of the two spikes in this Figure could be attributed to measurement error, as they occur at only two temperature points $\left(0^{\circ} \mathrm{C}\right.$ and $-170{ }^{\circ} \mathrm{C}$, well far from each other). Therefore, we can conclude that $I_{\text {ref }}$ is the major contributor to the output voltage degradation of the BGR circuit. As can be seen from Fig. 1, $I_{\text {ref }}$ is the amplified version of $I_{\mathrm{PTAT}}$ which is given in (1). In deriving (1), it has been assumed that the base 


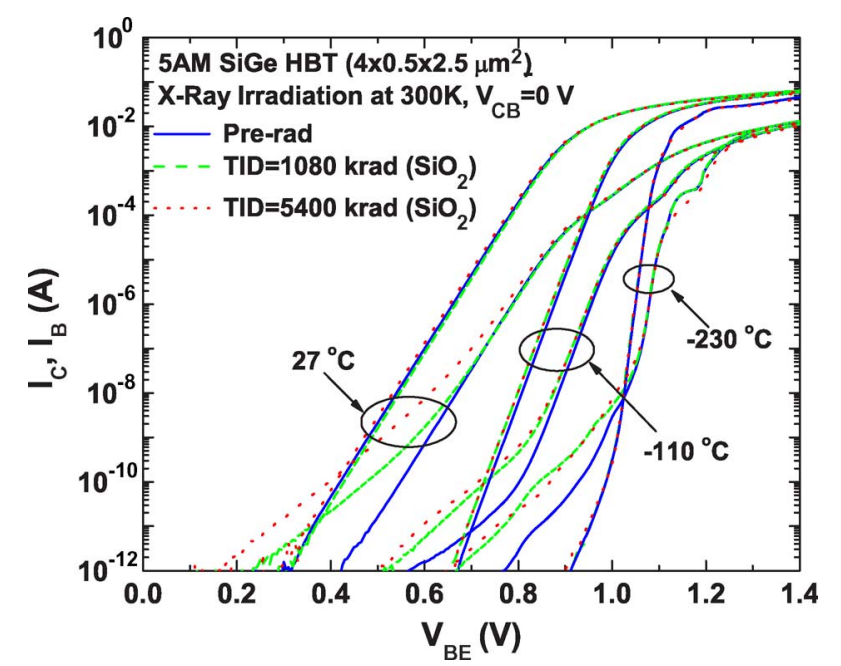

Fig. 10. Gummel characteristics before and after X-ray irradiation with TID levels of 1080 and $5400 \mathrm{krad}\left(\mathrm{SiO}_{2}\right)$.

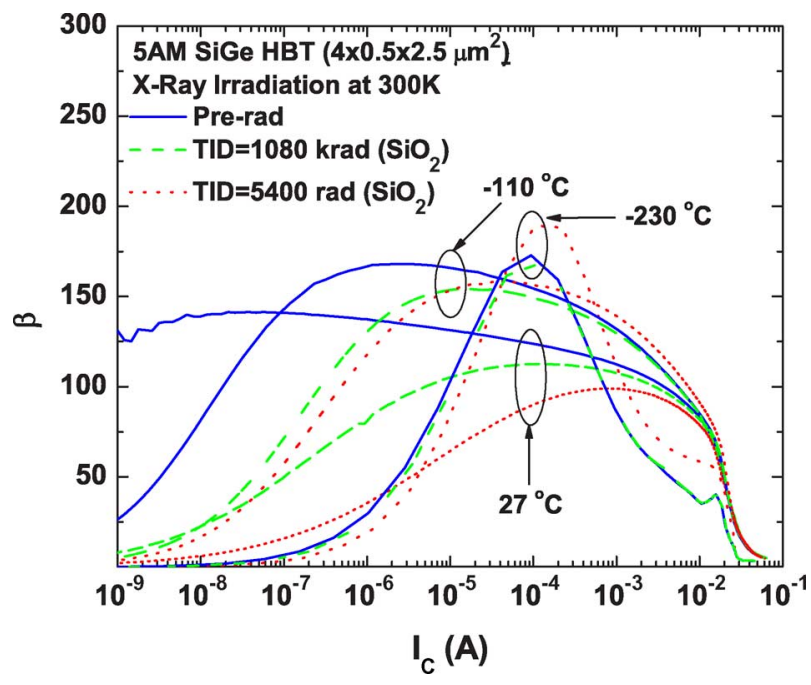

Fig. 11. Current gain before and after X-ray irradiation with TID levels of 1080 and $5400 \mathrm{krad}\left(\mathrm{SiO}_{2}\right)$.

current is negligible. However, as it has been discussed in [11], [12], the base leakage current increases after X-ray radiation and therefore, cannot be neglected after exposures to these dose levels. The increase in the post-irradiation base current is due to creation of positive charge in the emitter-base (EB) oxide spacer and increase in the number of traps at the EB spacer oxide/silicon interface, which results in increased surface recombination velocity [20]. To show this, four parallel copies of $0.5 \times 2.5 \mu \mathrm{m}^{2}$ device, similar to transistors $Q_{1}$ and $Q_{3}$ in the first-order BGR, were laid out, fabricated and measured prior to and subsequent to X-ray irradiation. The radiation experiment was performed while the transistors were under bias in the forward-active region. Fig. 10 shows the measured Gummel characteristics of such a device at three different temperatures, before and after X-ray irradiation. As expected, Fig. 10 indicates that the base current increases as the TID level increases. The current gain of this transistor as a function of collector current is shown in Fig. 11, indicating that the current gain significantly degrades after exposure to TID level of $5400 \mathrm{krad}\left(\mathrm{SiO}_{2}\right)$, specially when the transistor is biased in the low bias region. This is indeed the case with all of the SiGe HBTs in both BGR circuits, since at room temperature, they are all biased in the (25-50) $\mu \mathrm{A}$ region. We thus continue the circuit analysis of the first-order BGR taking into account the base currents of both transistors $Q_{1}$ and $Q_{2}$. In this case, the $I_{\mathrm{PTAT}}$ current can be expressed as

$$
I_{\mathrm{PTAT}}=\frac{V_{T}}{R_{1}} \ln \left[\left(1-\frac{2}{\beta}\right) \frac{A_{2}}{A_{1}}\right]-I B_{Q 2}
$$

where, $V_{T}$ is the thermal voltage, $\beta$ is the current gain, $A_{2} / A_{1}$ is the emitter area ratio of transistors $Q_{2}$ and $Q_{1}$ (equal to 8 in both BGR circuits) and $I B_{Q 2}$ is the base current of transistor $Q_{2}$. Equation (5) shows that any change in $I B_{Q 2}$ or $\beta$ will directly affect the magnitude of $I_{\mathrm{PTAT}}$. Note that any change in $I_{\mathrm{PTAT}}$ is multiplied by a factor of $k R_{2}$ and could cause a significant shift in the output voltage. This could in fact explain the observed TID dependence of output voltage degradation (Figs. 5 and 7). A radiation-induced increase in the base current and the consequent degradation of the current gain is much smaller for the TID level of $1080 \mathrm{krad}\left(\mathrm{SiO}_{2}\right)$ than for $5400 \mathrm{krad}\left(\mathrm{SiO}_{2}\right)$ (Figs. 10 and 11) and therefore, according to (5), it is expected that the shift in the output voltage becomes smaller when the circuit is exposed to TID levels of lower than $5400 \mathrm{krad}\left(\mathrm{SiO}_{2}\right)$, consistent with our data.

For the compensated BGR circuit, it is observed that the change in the magnitude of the output voltage is much larger compared to that of the first-order BGR, after X-ray radiation exposure. This observation can also be explained by analyzing the circuit and explicitly taking into account base current effects. As discussed in Section III, the output voltage of this circuit is estimated to be (4). The current $I_{\text {ref }}$ is equal to the summation of the collector current of transistor $Q_{5}, I C_{Q 5}$, and the base current of transistor $Q_{3}$. Transistors $Q_{1}$ and $Q_{5}$ are identical pairs and therefore

$$
I C_{Q 5}=I C_{Q 1}=I_{\mathrm{PTAT}}-I B_{Q 1}-I B_{Q 2}-I B_{Q 5}
$$

where $I B_{Q 1}, I B_{Q 2}$ and $I B_{Q 5}$ represent the base currents of transistors $Q 1, Q 2$ and $Q 5$, respectively. Similar to the analysis presented for the first-order BGR, the current $I_{\mathrm{PTAT}}$ in Fig. 3 can then be expressed as

$$
I_{\mathrm{PTAT}}=\frac{V_{T}}{R_{1}} \ln \left[\left(1-\frac{3}{\beta}\right) \frac{A_{2}}{A_{1}}\right]-I B_{Q 2} .
$$

Using (6) and (7) in (4), the output voltage of the compensated BGR can be written as

$$
\begin{aligned}
V_{\mathrm{ref}}=V_{\mathrm{BE}, 3} & +R_{2}\left(\frac{V_{T}}{R_{1}} \ln \left[\left(1-\frac{3}{\beta}\right) \frac{A_{2}}{A_{1}}\right]\right) \\
& +R_{2}\left(-2 I B_{Q 2}-I B_{Q 1}-I B_{Q 5}+I B_{Q 3}\right) .
\end{aligned}
$$

Assuming identical base currents for all the transistors, (8) can finally be simplified to

$$
V_{\mathrm{ref}}=V_{\mathrm{BE}, 3}+R_{2}\left(\frac{V_{T}}{R_{1}} \ln \left[\left(1-\frac{3}{\beta}\right) \frac{A_{2}}{A_{1}}\right]-3 I B_{Q 2}\right) .
$$

Equation (9) shows that any change in the base current after irradiation results in almost a $3 \times$ shift in the magnitude of the output voltage in the compensated BGR than in the first-order 
BGR. Also note that the value of resistor $R_{2}$ used in the compensated BGR is twice as large as the one used in the first-order BGR.

The discussion provided in this section clearly explains the reasons behind the observed sensitivity of the output voltage to both TID level and circuit topology. To prevent the post-irradiation degradation of the performance of these voltage references, circuit techniques need to be developed to minimize the dependency of the output voltage on the base current of the SiGe HBTs.

\section{PROTON IRRADIATION}

The effects of proton irradiation on the performance of $\mathrm{SiGe}$ voltage references has been previously investigated in [10] illustrating that proton-induced changes in the SiGe BGR circuits are minor up to a TID level of $3 \mathrm{Mrad}(\mathrm{Si})$. However, in the previous section, it was shown that X-Ray irradiation at high TID level of $5400 \mathrm{krad}\left(\mathrm{SiO}_{2}\right)$ can significantly degrade the performance of the BGR circuits. To investigate the impact of radiation source on the performance of $\mathrm{SiGe}$ voltage references, the compensated BGR which showed worse-case performance degradation under $\mathrm{X}$-ray exposure, was irradiated to the same effective TID level of $5400 \mathrm{krad}\left(\mathrm{SiO}_{2}\right)$ using $63 \mathrm{MeV}$ protons. Note that in the case of $63.3 \mathrm{MeV}$ protons, the equilibrium dose in $\mathrm{Si}$ and $\mathrm{SiO}_{2}$ differ by less than $5 \%$. In what follows the experimental procedure is explained and the circuit response to both protons and X-rays are compared.

\section{A. Experiment}

The $63.3 \mathrm{MeV}$ proton irradiation was performed at the Crocker Nuclear Laboratory at the University of California at Davis. The dosimetry measurements used a five-foil secondary emission monitor calibrated against a Faraday cup, and Ta scattering foils located several meters upstream of the target establish a beam spatial uniformity of $15 \%$ over a $2.0 \mathrm{~cm}$ radius circular area. The dosimetry system has been previously described [21], and is accurate to about $10 \%$. The circuit was irradiated while under operating bias to a TID level of 5400 $\operatorname{krad}\left(\mathrm{SiO}_{2}\right)$.

\section{B. Results and Discussion}

Measurement results prior to and subsequent to proton irradiation are illustrated in Fig. 12, showing that the output voltage of the compensated BGR has been lowered across temperature by less than $10 \mathrm{mV}$. Similar to the discussion given in the previous section, this post-rad degradation in the performance could be due to the fact that the base current of SiGe HBTs increases after proton irradiation. Fig. 13 shows the Gummel characteristics of the 5AM device at three different temperatures, before and after proton irradiation. This figure indicates that the base current leakage increases after proton irradiation for all three temperatures, and therefore, and according to (9), the magnitude of the output voltage should drop after irradiation, consistent with the data.

A comparison of Figs. 8 and 12 indicates that the degradation in the circuit performance is radiation source dependent and proton irradiation shows less degradation than X-ray irradiation.

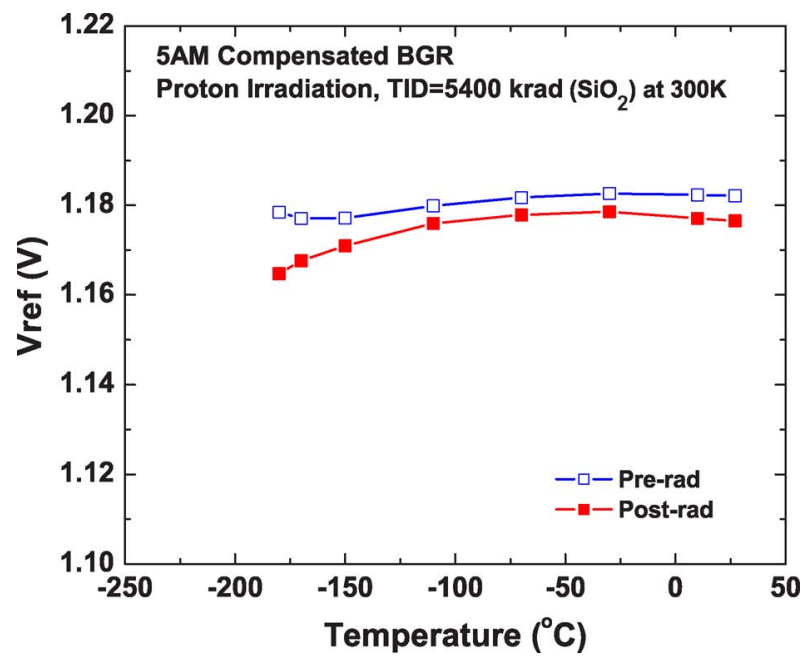

Fig. 12. Output voltage of compensated BGR before and after proton irradiation at $300 \mathrm{~K}$ with $\mathrm{TID}=5400 \mathrm{krad}\left(\mathrm{SiO}_{2}\right)$.

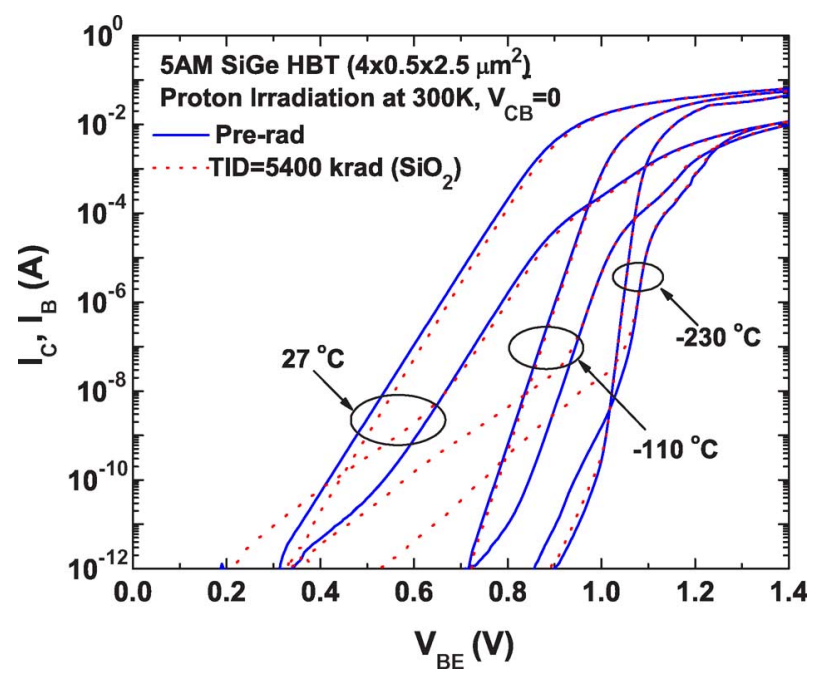

Fig. 13. Gummel characteristics before and after proton irradiation at $300 \mathrm{~K}$ with $\mathrm{TID}=5400 \mathrm{krad}\left(\mathrm{SiO}_{2}\right)$.

This difference could be attributed to the fact that at the transistor level, the increase in the base leakage current is smaller for protons than for X-rays, as discussed in [11], [12]. This is also observed by comparing Figs. 10 and 13 which show that at the base-emitter voltage of $0.7 \mathrm{~V}$, and at room temperature, the base current after X-ray exposure changes by almost $100 \mathrm{nA}$, while it changes by less than $20 \mathrm{nA}$ after proton irradiation (at the same effective dose). This difference in the degradation induced by X-rays and protons, as discussed in [11], may lie in dose enhancement effects, as low energy X-rays pass through high- $Z$ materials such as the copper layers and the tungsten vias of the metal interconnections.

\section{SUMMARY}

We have presented a comprehensive investigation of the performance dependencies of irradiated SiGe voltage reference circuits on TID level, circuit topology, and radiation source. Two different SiGe bandgap voltage reference topologies were designed and exposed to X-rays at TID levels of 
$1080 \mathrm{krad}\left(\mathrm{SiO}_{2}\right)$ and $5400 \mathrm{krad}\left(\mathrm{SiO}_{2}\right)$. The degradation in circuit performance after X-ray irradiation was observed to be dependent on both the circuit topology and the TID level. $\mathrm{X}$-ray exposure to large TID levels significantly decreased the magnitude of the output voltage. Explanations for the observed anomalies were provided using detailed analysis of the two circuit topologies. It was found that the excess base leakage current is the primary factor that affects post-irradiation performance degradation. The circuit topology that showed the worst-case degradation from the $\mathrm{X}$-ray experiment was irradiated with $63.3 \mathrm{MeV}$ proton at $5400 \mathrm{krad}\left(\mathrm{SiO}_{2}\right)$ TID. Proton and X-ray post-rad circuit responses were compared. At the same TID level, X-ray irradiation was shown to degrade the circuit performance more than proton irradiation. This radiation-source dependence was also attributed to differences in the excess base current leakage. The results presented in this paper show that ultra-high-dose irradiation can significantly degrade the performance of precision voltage references implemented in SiGe technology. To prevent post-irradiation performance degradation, circuit topologies have to be carefully chosen and circuit techniques need to be applied to minimize the dependency of the output voltage on the transistor base current.

\section{ACKNOWLEDGMENT}

The authors would like to thank M. Watson, D. Frazier, A. Keys, D. Hope, K. LaBel, L. Cohn, A. Joseph, the NASA SiGe ETDP team, and the SiGe team at IBM for their contributions and support of this work. The authors are grateful to D. Fleetwood and R. Schrimpf for providing X-Ray facility support under the MURI program.

\section{REFERENCES}

[1] J. D. Cressler and G. Niu, Silicon-Germanium Heterojunction Bipolar Transistors. Boston, MA: Artech House, 2003.

[2] B. G. Rax, C. I. Lee, and A. H. Johnston, "Degradation of precision reference devices in space environments," IEEE Trans. Nucl. Sci., vol. 44, no. 6, pp. 1939-1944, Dec. 1997.

[3] S. S. McClure, J. L. Gorelick, R. L. Pease, B. G. Rax, and R. L. Ladbury, "Total dose performance of radiation hardened voltage regulators and references," in IEEE Radiation Effects Data Workshop Rec., Jul. 2001, pp. $1-5$.

[4] M. V. O’Bryan, K. A. LaBel, R. A. Reed, J. W. Howard, R. L. Ladbury, J. L. Barth, S. D. Kniffin, C. M. Seidleck, P. W. Marshall, C. J. Marshall, H. S. Kim, D. K. Hawkins, A. B. Sanders, M. A. Carts, J. D. Forney, D. R. Roth, J. D. Kinnison, E. Nhan, and K. Sahu, "Radiation damage and single event effect results for candidate spacecraft electronics," in IEEE Radiation Effects Data Workshop Rec., Jul. 2000, pp. $106-122$.

[5] H. J. Barnaby, R. D. Schrimpf, A. L. Sternberg, V. Berthe, C. R. Cirba, and R. L. Pease, "Proton radiation response mechanisms in bipolar analog circuits," IEEE Trans. Nucl. Sci., vol. 48, no. 6, pp. 2074-2080, Dec. 2001.
[6] A. H. Johnston, B. G. Rax, and C. I. Lee, "Enhanced damage in linear bipolar integrated circuits at low dose rate," IEEE Trans. Nucl. Sci., vol. 48, no. 6, pp. 2074-2080, Dec. 2001.

[7] S. S. McClure, R. L. Pease, W. Will, and G. Perry, "Dependence of total dose response of bipolar linear microcircuits on applied dose rate," IEEE Trans. Nucl. Sci., vol. 41, no. 6, pp. 2544-2549, Dec. 1994.

[8] R. L. Pease, W. E. Combs, A. Johnston, T. Carriere, and S. S. McClure, "A compendium of recent total dose data on bipolar linear microcircuits," in IEEE Radiation Effects Data Workshop Rec., Jul. 1996, pp. $28-37$.

[9] J. D. Cressler, M. C. Hamilton, R. Krithivasan, H. Ainspan, R. Groves, G. Niu, S. Zhang, Z. Jin, C. J. Marshall, P. W. Marshall, H. S. Kim, R. A. Reed, M. J. Palmer, A. J. Joseph, and D. L. Harame, "Proton radiation response of SiGe HBT analog and RF circuits and passives," IEEE Trans. Nucl. Sci., vol. 48, no. 6, pp. 2238-2243, Dec. 2001.

[10] L. Najafizadeh, M. Bellini, A. P. G. Prakash, G. A. Espinel, J. D. Cressler, P. W. Marshall, and C. J. Marshall, "Proton tolerance of SiGe precision voltage references for extreme temperature range electronics," IEEE Trans. Nucl. Sci., vol. 53, no. 6, pp. 3210-3216, Dec. 2006.

[11] A. K. Sutton, A. P. G. Prakash, B. Jun, E. Zhao, M. Bellini, J. Pellish, R. Diestelhorst, M. A. Carts, A. Phan, R. Ladbury, J. D. Cressler, P. W. Marshall, C. J. Marshall, R. A. Reed, R. D. Schrimpf, and D. M. Fleetwood, "An investigation of dose rate and source dependent effects in $200 \mathrm{GHz}$ SiGe HBTs," IEEE Trans. Nucl. Sci., vol. 53, no. 6, pp. 3166-3174, Dec. 2006.

[12] M. Bellini, B. Jun, T. Chen, J. D. Cressler, P. W. Marshall, D. Chen, R. D. Schrimpf, D. M. Fleetwood, and J. Cai, "X-ray irradiation and bias effects in fully-depleted and partially-depleted SiGe HBTs fabricated on CMOS-compatible SOI," IEEE Trans. Nucl. Sci., vol. 53, no. 6, pp. 3182-3186, Dec. 2006.

[13] J. M. Roldan, G. Niu, W. E. Ansley, J. D. Cressler, S. D. Clark, and D. C. Ahlgren, "An investigation of the spatial location of proton-induced traps in SiGe HBTs," IEEE Trans. Nucl. Sci., vol. 45, no. 6, pp. 2424-2429, Dec. 1998.

[14] A. P. G. Prakash, A. Sutton, R. Diestelhorst, G. Espinel, J. Andrews, B. Jun, J. D. Cressler, and C. J. Marshall, "The effect of irradiation temperature on the proton response of SiGe HBTs," IEEE Trans. Nucl. Sci., vol. 53, no. 6, pp. 3175-3181, Dec. 2006.

[15] P. R. Gray and R. G. Meyer, Analysis and Design of Analog Integrated Circuits, 4th ed. New York: Wiley, 2001.

[16] I. Lee, G. Kim, and W. Kim, "Exponential curvature-compensated BiCMOS bandgap references," IEEE Journal of Solid-State Circuits, vol. 29, pp. 1396-1403, Nov. 1994.

[17] G. A. Rincon-Mora and P. E. Allen, "A 1.1 V current-mode and piecewiselinear curvature corrected bandgap reference," IEEE J. Solid-State Circuits, vol. 33, no. 10, pp. 1551-1554, Oct. 1998.

[18] B. S. Song and P. R. Gray, "A precision curvature-compensated CMOS bandgap reference," IEEE J. Solid-State Circuits, vol. 18, no. 6, pp. 634-643, Dec. 1983.

[19] K. N. Leung, P. K. T. Mok, and C. Y. Leung, "A 2-V $23 \mu \mathrm{A}$ 5.3- $\mathrm{ppm} /{ }^{\circ} \mathrm{C}$ curvature-compensated CMOS bandgap voltage reference," IEEE J. Solid-State Circuits, vol. 38, no. 3, pp. 561-564, Mar. 2003.

[20] R. N. Nowlin, E. W. Enlow, R. D. Schrimpf, and W. E. Combs, "Trends in the total-dose response of modern bipolar transistors," IEEE Trans. Nucl. Sci., vol. 39, no. 6, pp. 2026-2035, Dec. 1992.

[21] P. W. Marshall, C. J. Dale, M. A. Carts, and K. A. LaBel, "Particleinduced bit errors in high performance fiber optic data links for satellite data management," IEEE Trans. Nucl. Sci., vol. 41, no. 6, pp. 1958-1965, Dec. 1994. 